\title{
Procurement and Supply of Anti Snake Venom as a Determinant of Snake Bite Management Outcome at a Government Medical College Hospital in Karnataka
}

\author{
Siddaya Ramakrishna ${ }^{1}$, Puttamaligaiah Subhas Babu ${ }^{2}$
}

\section{Siddaya Ramakrishna', Puttamaligaiah Subhas Babu $^{2}$}

'Department of General Medicine, Mandya Institute of Medical Sciences, Mandya, Karnataka, India.

${ }^{2}$ Department of Community Medicine, Mandya Institute of Medical Sciences, Mandya, Karnataka, India.

*'These authors contributed equally to this work."

\author{
Correspondence \\ P Subhas Babu \\ Department of Community Medicine, \\ Mandya Institute of Medical Sciences, \\ Mandya \\ Phone numbers 9481889628 \\ E-mail address: p.subhash.babu@gmail. \\ com \\ History \\ - Submission Date: 03-09-16 \\ - Revised Date: 02-01-17 \\ - Accepted Date: 14-01-17
}

DOI : 10.5530/ijmedph.2017.1.8

Article Available online

http://www.ijmedph.org/v7/i1

Copyright

(C) 2017 Phcog.Net. This is an openaccess article distributed under the terms of the Creative Commons Attribution 4.0 International license.

\begin{abstract}
Context: Snake bite poisoning, is an important reason for hospitalization and death in rural India. Availability and timely administration of anti snake venom (ASV) at hospitals is an important factor in favourable prognosis for snake bite victims.

Aims: To determine

i. proportion of venomous bites to non venomous bites

ii. proportion of snake bite cases administered Anti snake venom

iii. supply and utilization of Anti snake venom in one year period for treating snake bite victims Settings and Design: A Cross sectional, study was conducted in a Government Medical college hospital in Mandya, Karnataka from November 2012 to October 2013 to ascertain ASV utilization. Methods and Material: Data was collected from hospitalized snake bite victims, from medico legal register (deaths) and in-patient records. Information on ASV stock and supplies, was obtained from the hospital main stores and ward indents.

Statistical analysis used: Frequencies and Proportions. Results: 376 (n) snake bite cases were admitted to the hospital during the period, of which 77 victims $(20.47 \%)$ had envenomation (including 4 deaths). Of 920 anti snake venom vials procured and supplied to the hospital, 915 vials were used, of which 531 vials (58.03\%) were administered to those correctly diagnosed to have envenoming. 189 (50.13\%) victims who were later diagnosed not to have envenoming, received 384 vials (41.97\%). Conclusions: ASV utilization is complete and on a few occasions excessive. All cases of envenoming were not given 10 vials of ASV as suggested in the protocol. Some cases received 2 vials at admission and recovered.
\end{abstract}

Key Messages: Administration of full dose of Anti snake venom to snake bite victims is constrained by stocks and availability of ASV.

Though the Indian snake bite management protocol recommends an initial dose of 10 ASV vials, in the present state of mismatched case load and available base stock of anti snake venom in hospital stores, calls for prudence in ASV usage by the treating physicians.

Key words: Anti-snake Venom, Envenoming, Mismatch, Stock, Supply, Utilization

\section{INTRODUCTION}

Worldwide envenoming and deaths due to snakebites ranges from 421,000 and 20,000 respectively to as high as 1,841,000 envenomings and 94,000 deaths annually. The most complete data suggest that envenomed bites constitute $18 \%$ and $30 \%$ of the total snake bites in India and Pakistan, respectively. As per an estimate total number of snakebites is two to three times the number of envenomings. ${ }^{1}$

Poisoning due to snake bite is an important reason for hospitalization and death in rural India. Rural population is at a relatively higher risk for snake bite as rural environmental settings provide a more favorable habitat for snakes and a higher chance for human and snake contact, compared to urban settings.
In India 45,900 deaths were attributed to snake bite in 2005 (99\% CI 40,900 to 50,900) or an annual agestandardized rate of $4.1 / 100,000$ (99\% CI 3.6-4.5), with higher rates in rural areas $(5.4 / 100,000 ; 99 \%$ CI 4.8-6.0). Karnataka has been categorized as a high prevalence state for snake bite deaths with annual snake bite death rate of 4.2 per 100,000 population. $^{2}$

Adequate distribution of anti-venoms is a matter of great concern in many regions of the world. To ensure an appropriate supply for clinical use, inventories should be in excess of the estimated number of cases, to allow for unpredictable surges in local demand, accepting that some anti venoms will not have been used by the time of their expiry date. ${ }^{3}$

Anti snake venom (ASV) used in India is polyvalent i.e. it is effective against all the four com- 
mon species; Russells viper, Common Cobra, Common Krait and Saw Scaled viper. There are no objective means of identifying the snake species, in the absence of the dead snake. It has been suggested that hospitals that cater to geographical regions where snake bites are common, maintain an adequate stock of anti snake venom. ${ }^{4}$

As per the Indian National Snake bite management protocol low dose strategies have no role nor do high dose strategies, and it is imperative to start with 10 vials as a standard. Assuming that is the minimum dose required to neutralise a viper bite which injects around $63 \mathrm{mg}$ of venom on an average. ${ }^{4}$

\section{The study was taken up with the following objectives}

To determine

1. The proportion of venomous bites to non venomous bites

2. The proportion of snake bite cases requiring anti snake venom

3. The supply and utilization of anti snake venom in a one year period for treating patients admitted for treatment of snake bite.

\section{Subjects and Methods:}

\section{Study setting}

Government tertiary care hospital at a district head quarters in southern Karnataka

\section{Study population}

Victims of snake bite as identified by personal history, who come to the hospital seeking care.

\section{Study sample}

All cases of snake bite who reported and were treated at the tertiary care hospital in a one year period.

\section{Study duration}

1 year (November 2012 to October 2013)

\section{Study type}

Cross sectional, descriptive study. Data was collected from the victims of snake bite by personal interview, using a pre tested structured questionnaire at the time of admission or during their stay at the hospital. The victims were interviewed by the investigators or interns working in Medicine and Casualty departments. All the data collectors were oriented on the questionnaire to ensure validity of data. Informed consent was obtained prior to interview. Information on snake bite victims was also obtained from Medico Legal register (in case of deaths) and in-patient case records from the Medical Records Department. Information on ASV stock and supplies to casualty and medicine wards was obtained from the Main stores of the hospital pharmacy and indent books from the wards.

The study was approved by the Institutional Ethics Committee.

\section{Statistical analysis}

Frequencies and proportions

\section{RESULTS}

Total number of snake bite cases admitted to MIMS hospital during the period - $376(\mathrm{n})$

Of all the 376 patients who came with a history of snake bite, a total of $77(20.48 \%)$ patients were confirmed to have envenoming (based on history, presence of fang/ bite marks at alleged sites of bite and other clinical signs and symptoms) of which $4(1.06 \%)$ patients died due to

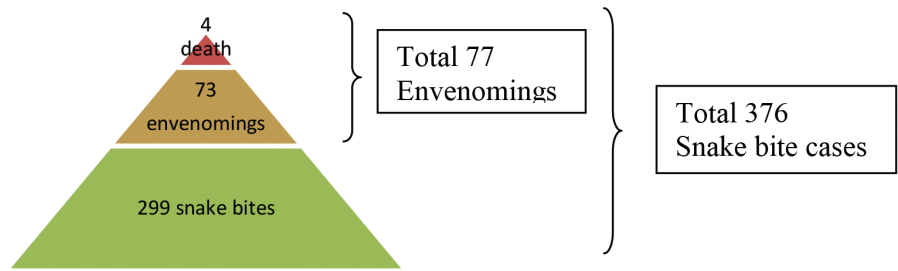

Figure 1: Number of snake bite victims, envenoming and snake bite deaths (original)

Table 1: Number of snake bite victims with envenomation and without envenomation who received and did not receive anti snake venom

$\begin{array}{cccc} & \text { Recieved ASV } & \text { Did not receive ASV } & \text { Total } \\ \begin{array}{c}\text { Snake bite } \\ \text { envenomation }\end{array} & 75 \text { (2 deaths) } & 2 \text { (brought dead) } & 77 \\ \begin{array}{c}\text { Snake bite No } \\ \text { envenomation }\end{array} & 189 & 110 & 299 \\ \text { Total } & 264 & 112 & 376\end{array}$

envenoming (of the 4 deaths 2 were declared dead even before admission). The number of male patients was $262(69.68 \%)$ and females were $114(30.32 \%)$. A total of 264 (70.74\%) snake bite victims including those confirmed of snake bite poisoning $(n=75)$ were administered anti snake venom based on the history of snake bite and presence of fang marks ( 2 snake bite victims who were brought dead are not included in those administered ASV).

299 cases were declared as no envenoming, and 110 of them were correctly not administered ASV. But 384 vials of ASV was administered to 189 of these cases based on history of snake bite and local findings (fang marks, oedema etc) at the alleged site of bite (also the apprehension of the patient attendants that patient has not been given ASV despite patient being brought to a higher centre).

In Table No. 2, the third column depicts the number of ASV vials procured and the fourth column depicts the number supplied to the wards/ casualty. On some occasions there has been excess requirement of ASVs which has been met by the patient attendants bringing the vials from outside which is reflected as a negative balance in the last column in the table. The procurement of ASVs in the month of March 2013 has been more and relatively lesser number of vials being used in the month of April 2013, the ASVs in the wards/ casualty supplied earlier has been utilized. Column four is actually the total number of vials available for use in the wards/ casualty including the vials supplied in the previous month. A total of 531 vials of ASV were given to 75 victims who were correctly diagnosed to have envenoming. One patient diagnosed to have envenoming and was administered ASV, but had to be discontinued as he developed reaction to ASV. The average number of vials used per patient confirmed to have envenoming was 7.08 vials or approximately $72 \mathrm{ml}$ of ASV (the Median number of vials was 1). Whereas the average number of vials received by those who were diagnosed not to have envenoming was 2.03 vials which could have been eliminated or minimized. The maximum number (3 patients out of 189) of vials received by those not diagnosed to have envenoming was 10 vials, whereas the maximum number of vials used in those confirmed to have envenoming (1 patient out of 75 patient) was 36 vials. 
Table 2: Showing Stock of Anti snake venom at Hospital main stores, supplies to Medicine wards and Casualty and number of snake bite victims administered ASV during 2012 November to 2013 October (original)

\begin{tabular}{|c|c|c|c|c|c|c|c|}
\hline SI. No & Month & $\begin{array}{l}\text { ASV Stocks } \\
\text { procured }\end{array}$ & $\begin{array}{l}\text { Number of vials of } \\
\text { ASV } \\
\text { Supplied to wards/ } \\
\text { casualty }\end{array}$ & $\begin{array}{c}\text { Total number } \\
\text { of snake bite } \\
\text { cases }\end{array}$ & $\begin{array}{c}\text { Total number } \\
\text { of cases given } \\
\text { ASV }\end{array}$ & $\begin{array}{l}\text { No. of ASV } \\
\text { vials used }\end{array}$ & $\begin{array}{l}\text { Remaining stock } \\
\text { in wards/ Casualty }\end{array}$ \\
\hline 1 & Oct 2012 & 120 & 120 & & & & \\
\hline 2 & Nov 2012 & & - & 38 & 35 & 137 & -17 \\
\hline 3 & Dec 2012 & 110 & 110 & 34 & 27 & 120 & -10 \\
\hline 4 & Jan 2013 & 52 & 52 & 22 & 18 & 35 & 17 \\
\hline 5 & Feb 2013 & - & - & 12 & 1 & 08 & 09 \\
\hline 6 & Mar 2013 & 217 & 110 & 38 & 28 & 103 & 16 \\
\hline 7 & Apr 2013 & 102 & 56 & 47 & 30 & 97 & -15 \\
\hline 8 & May 2013 & 8 & 127 & 45 & 22 & 84 & 43 \\
\hline 9 & Jun 2013 & 75 & 76 & 31 & 18 & 52 & 67 \\
\hline 10 & Jul 2013 & 87 & 62 & 26 & 21 & 104 & 25 \\
\hline 11 & Aug 2013 & 138 & 85 & 36 & 23 & 76 & 34 \\
\hline 12 & Sep 2013 & 09 & 120 & 28 & 27 & 60 & 94 \\
\hline \multirow[t]{2}{*}{13} & Oct 2013 & 02 & & 19 & 14 & 39 & 55 \\
\hline & Total & 920 & 918 & 376 & 264 & 915 & \\
\hline
\end{tabular}

\section{DISCUSSION}

The proportion of venomous bites (20.48\%) among all snake bites as observed in our study is similar to results as mentioned in an article by Kasturiratne et al

A community-based study in Bangladesh found about 100 non-fatal bites for each death. ${ }^{5}$

As evident in our study 189 patients $(50.26 \%, \mathrm{n}=376)$ were administered anti snake venom but later found that there was no envenoming. This is due to the fact that snake bite being a life threatening event the treating physician would prefer to err on the safer side rather than not taking the chance at all. (Despite the knowledge of snake bite management guidelines) Hence the victims were started on a low dose of ASV as evident from the study results.

In a study done in Myanmar by Myo-Khin et al., the initial amount of ASV received was $20 \mathrm{ml}$ in 51 cases (51\%), $40 \mathrm{ml}$ in 35 (35\%), $10 \mathrm{ml}$ in $14(14 \%)$ and $50 \mathrm{ml}$ in one case (1\%). On an average (SD), $25.6(11.3) \mathrm{ml}$ of ASV was given initially; median dose being $20 \mathrm{ml}$. During the course of the treatment up to $120 \mathrm{ml}$ of ASV was given at the hospital. On average (SD), 43.9 (39.0) $\mathrm{ml}$ of ASV was used per snakebite case (median $40 \mathrm{ml}$ ). ${ }^{6}$ As for the stocks of anti snake venom in the hospital stores for distribution to casualty and wards, the status was as per the table mentioned above. But for an institution at the tertiary level, the holding quantity for lyophilized Anti Snake venom, required as per the Indian National Snake bite management guidelines is as follows. ${ }^{4}$

$(x d X 1.2) t$ where:

$\mathrm{x}=$ number of envenomings on average per month

$\mathrm{d}=$ the maximum number of vials likely to be administered at the institution to a single patient

$\mathrm{t}=$ length of time normally experienced for replenishment in months.

Here the number of actual envenomings per month was rounded off to 7 (considering 77 cases of envenoming in a one year period). In India the maximum dose for a patient at a PHC would be 2 doses of 10 vials for a neurotoxic patient, so $\mathrm{d}=20$.
1.2 represents the safety factor to ensure availability of greater than minimal stock. The restocking time in months is represented by $t$. The restocking period was 1 month for AV/ASV to be replaced, for our institution. Ideally the base stock in any month for ASV should be [7 X 20 X 1.2 X $1=168$ ]

As per the Indian National Snake bite protocol 2007, the recommended base stock for ASV every month has to be at least 168 vials as calculated from the above mentioned formula, but in our study, except during the month of March 2013 base stocks have never crossed this mark. Probably many centres in India would struggle to maintain this because of difficulty in procuring stocks. In our own hospitals stock were mobilised from nearby District hospital, Taluk level hospitals, Community health centres which otherwise would not have been used, due to lesser case load. Also smaller stock of less than 5 ASV vials which had not been used and otherwise would have crossed expiry dates, was also handed over from nearby Primary Health Centres. Similar to observations made in the WHO guidelines for production, control and regulation of antisnake venom immunoglobulins, procurement of ASV was a matter of concern in our institution which has been an important determinant in snake bite management.

As observed in the study by Kasturiratne A et al, even bites by nonvenomous snakes or bites by a venomous snake that do not cause envenoming may pose a burden on health systems, because in some regions victims access the health care system and require assessment. ${ }^{1}$ So, despite the victims being diagnosed not to have envenoming at a later juncture, ASV was administered as an initial intervention to victims who came with a history of snake bite. In one of the studies from Kerala, only $34 \%$ of cases with proven snake bites $(n=586)$ actually developed signs of envenoming. ${ }^{7}$ The symptoms initially found in snake bite victims because of the stress and panic due to snake bite itself may actually pose difficulties to the clinicians to differentiate them from early signs of envenoming. ${ }^{8}$ In this study though only $31.36 \%$ of those who received anti snake venom $(n=264)$ actually had envenoming, it is ensured that all persons who had envenoming were administered anti-snake venom. 


\section{CONCLUSION}

Though the time taken by a snake bite victim to reach a hospital is the most important factor for a favorable prognosis, also important is the ready availability of anti snake venom at the institution. Administration of full dose of Anti snake venom to snake bite victims also depends on stocks and availability of ASV apart from need for anti snake venom, as determined by clinical features.

Though the Indian snake bite management protocol recommends an initial dose of 10 ASV vials, the present state of mismatched case load and available base stock of anti snake venom in hospital stores, calls for prudence in ASV usage by the treating physicians and ensure ASV is only administered to those with envenoming.

Base stock should be adequate to meet the ASV requirements taking into account the restocking period. The results call for further studies to be taken up at multiple hospitals in different regions of the country to assess issues related to adherence to the Indian Snake bite management protocol keeping in mind the demand and supply of Anti Snake venom.

\section{ACKNOWLEDGEMENTS}

Professor and HoD, Department of General Medicine, staff and interns who assisted in data collection Staff of the Department of Medical Records Department

\section{CONFLICT OF INTEREST}

None

\section{ABBREVIATIONS USED}

AV: Antivenom; ASV - Anti snake venom; MIMS: Mandya Institute of Medical Sciences; PHC: Primary Health center.

\section{REFERENCES}

1. Kasturiratne A, Wickremasinghe $A R$, de Silva N, Gunawardena NK, Pathmeswaran A, et al. (2008) The global burden of snakebite: A literature analysis and modelling based on regional estimates of envenoming and deaths. PLoS Med 5(11): e218. doi:10.1371/journal.pmed.0050218; https://doi. org/10.1371/journal.pmed.0050218.

2. Mohapatra B, Warrell DA, Suraweera W, Bhatia P, Dhingra N, et al. (2011) Snakebite Mortality in India: A Nationally Representative Mortality Survey. PLoS Negl Trop Dis 5(4):e1018 doi:10.1371/journal.pntd.0001018; https://doi.org/10.1371/ journal.pntd.0001018.

3. WHO Guidelines for the Production, Control and Regulation of Snake Antivenom Immunoglobulins WHO Press, World Health Organization, 20 Avenue Appia, 1211 Geneva 27, Switzerland pg 74 available from URL http://www.who.int/ bloodproducts/snake_antivenoms/SnakeAntivenomGuideline. pdf (last accessed on 16.08.2016 at 1015hrs)

4. National Snakebite Management Protocol, Directorate General of Health Services, Ministry of Health and Family Welfare, Government of India; 2009. Available from: http://www.statehealthsocietybihar.org/nationalsnakebitemanagementprotocol. pdf [Last accessed on 2013 Nov 23].

5. Rahman R, Faiz MA, Selim S, Rahman B, Basher A, Jones A, et al. Annual incidence of snake bite in rural Bangladesh. PLoS Negl Trop Dis 2010;4:e860. https://doi.org/10.1371/journal.pntd.0000860.

6. Myo-Khina, Theingi-Nyuntb, Nyan-Tun-Ooc, Ye-Hlad. Prognostic indicators in patients with snakebite: analysis of two-year data from a township hospital in central Myanmar. WHO South-East Asia Journal of Public Health. 2012;1 (2):144-50 available from URL http://www.searo.who.int/publications/journals/seajph/ media/2012/seajph_v1n2/whoseajphv1i2p144.pdf?ua=1 (last accessed 16.08.2016 at $1000 \mathrm{hrs}$.

7. Suchithra N, Pappachan JM, Sujathan P (2008) Snakebite envenoming in Kerala, south India: clinical profile and factors involved in adverse outcomes. Emerg Med J 25:200-4. doi:10.1136/emj.2007.051136 available from URL http://emj. bmj.com/content/25/4/200.abstract (last accessed 26.11.2016 at 0054hrs) https://doi.org/10.1136/emj.2007.051136.

8. Alirol E, Sharma SK, Bawaskar HS, Kuch U, Chappuis F (2010) Snake Bite in South Asia: A Review. PLoS Negl Trop Dis. 4(1):e603. https://doi.org/10.1371/ journal.pntd.0000603.

Cite this article : Ramakrishna S, Babu PS. Procurement and supply of anti snake venom as a determinant of snake bite management outcome at a Government Medical college hospital in Karnataka. Int J Med. Public Health. 2017; 7(1): 47-50. 